\title{
Executing on a customer engagement strategy
}

\author{
Rajkumar Venkatesan ${ }^{1}$
}

Published online: 18 January 2017

(C) Academy of Marketing Science 2017

\section{Introduction}

The relationships between a firm and its customers are ever evolving, with growing opportunities to connect to other customers and firms through social media and mobile devices. Increased competition and advances in technology that are reducing barriers to entry have motivated firms to adopt several strategies to build a deeper level of attachment with their customers. Such a strategy is now termed as "customer engagement." Reflective of the trend toward customer engagement, this special issue on "Understanding and Managing Customer Engagement through Customer Relationship Management" presents a set of studies that lay the foundations of a new literature that I believe is poised to grow in importance and impact. These papers provide definitions of customer engagement and develop theoretical frameworks that identify the drivers and consequences of customer engagement (Pansari and Kumar 2017; Harmeling et al. 2017; Homburg et al. 2017).

As the academic field is developing the concept of customer engagement and its nomological distinction from other concepts such as loyalty and service dominant logic (Hollebeek et al. 2017), firms are experimenting with strategies that could develop relationships with their customers beyond just monetary transactions. Consider the company Amazon.com and its attempts to develop customer engagement, for instance by developing Amazon Dash, a device that can be paired with a

Rajkumar Venkatesan

VenkatesanR@darden.virginia.edu

1 Ronald Trzcinski Professor of Business Administration, Darden School of Business, University of Virginia, Charlottesville, VA, USA product of a consumer's choice and allows the consumer to reorder these products at the push of a single button. The objective here is to introduce a device that embeds with consumers' everyday routines and improves customer retention rate, share of wallet, purchase frequency, and ultimately customer lifetime value (CLV). To improve referrals, Amazon allows consumers to "get $\$ 5$ when your friends join Prime," 1 and the Amazon associates ${ }^{2}$ program allows participants to advertise products and earn up to $10 \%$ in referral fees. In 2005, Amazon launched a crowdsourcing marketplace called Amazon Mechanical Turk (mTurk) to improve improve feedback from customers and also learn from customers' knowledge about products. The marketplace allows employers to post jobs and workers to select jobs and complete them in exchange for payment. ${ }^{3}$ Open to any company, the service can ultimately help Amazon and its customers to gain knowledge from the jobs that are offered. Customers' reviews, an integral part of the Amazon post-purchase experience, significantly improve the influence its customers can have on each other. Amazon provides opportunities for its customers to interact with Amazon directly and with other current and potential Amazon customers.

The above example shows how customers are now continually connected to other customers and firms, through the internet, mobile applications, e-commerce platforms, and social networks. As firms adopt strategies to enable interactions among the triad of the customer, firm, and other customers, measuring and managing the value of customer engagement $(\mathrm{CEV})$ becomes a strategic imperative. A recent Gallup research study shows that engaged customers offer a $23 \%$ premium in terms of share of wallet, profitability, revenue, and relationship growth over the average customer across retail,

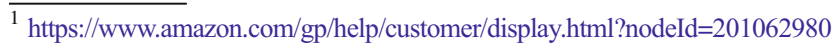

${ }^{2} \mathrm{https} / / /$ affiliate-program.amazon.com

${ }^{3}$ https://www.mturk.com/mturk/welcome
} 
consumer electronics, and hospitality industries (Pansari and Kumar 2017). ${ }^{4}$ And while only 58\% of executives in a 2016 Convero survey claimed to have a formal customer engagement program in place, $74 \%$ of the executives said they would increase spending on customer engagement over the next year. ${ }^{5}$

Over the last decade several academic articles have defined customer engagement from different perspectives. A common thread in these definitions is the fundamental assumption that customers are valuable to a firm in many ways in addition to his or her transactions. This is an evolution of the relationship marketing perspective wherein a customer's transactions with a firm is the base for a broader mutually beneficial relationship spanning word of mouth, and co-creation of new products.

Several studies in this issue, namely, Pansari and Kumar (2017), Harmeling et al. (2017), Homburg et al. (2017), and Menguc et al. (2017) focus on how firms can develop customer engagement through marketing and employee engagement. This is a first step in a critical direction toward value creation for different customer types. In this editorial I propose that academics and practitioners can benefit from combining the perspectives of customer experience (Lemon and Verhoef 2016) and engagement literatures. I base this on the following process-based premise: Customer relationships evolve through different states that can be broadly categorized as acquisition, growth, retention, and win-back. Customers engage in repeated journeys with the firm and their social networks in each state. This synergy between short-term experiences and the accumulation of such experiences that lead to progression in relationship states lead to different levels of customer engagement. My perspective is also reflective of the emphasis of Homberg et al. (2017) on touch point journeys across firms' mindsets, strategy, and capabilities.

Current research has a good understanding of experiences from pre-purchase to post-purchase that can lead to repeated transactions and can maximize customer lifetime value (CLV). But the role of experiences in creating value for customers to advocate for a brand or provide information that can allow brands to develop better and newer products is unknown. Managing this multidimensional perspective on the customer experience and journey maps is exactly what is needed to develop customer engagement-based business models and processes.

I next propose a framework for developing a journey mapbased view of customer engagement. Another aim of the framework is to be enable managers to build an engagement-oriented firm. I highlight some of the managerial implementation issues in the conclusion section. ${ }^{6}$

\footnotetext{
$\overline{{ }^{4} \mathrm{http}: / / \text { www.gallup.com/services/169331/customer-engagement.aspx }}$

52016 Convero customer engagement study; https://sessioncam. com/customer-engagement-stats-2016/

${ }^{6}$ The ideas presented here are adapted from Venkatesan et al. (2016).
}

\section{Research framework}

Creating an organizing framework for executing on a customer engagement strategy involves mapping the different stages of customer relationships (acquisition, growth, retention, and win-back) alongside customer journey stages (pre-purchase, purchase, and post-purchase). Table 1 provides such an organizing framework. For each combination of relationship and journey state, a firm can identify the ideal customer types to target, and the objective of the customer experience. For example, firms looking to acquire high lifetime value customers in the pre-purchase phase should provide different experiences than when they are trying to acquire those expected to influence other customers.

I next discuss outstanding research opportunities for each relationship stage. To do this I adopt Kumar et al.'s (2010) framework for customer engagement value (CEV). The framework takes the perspective of a firm that needs to make decisions to manage current and potential customers using the four key metrics; customer lifetime value (CLV), customer referral value (CRV), customer influence value (CIV), and customer knowledge value (CKV).

\section{Research agenda}

\section{Acquisition}

The majority of research to this point has focused on the value that is derived from new customer purchase behavior (i.e., CLV of a potential customer). Relatively little research has addressed how firms can leverage CIV and CKV during customer acquisition efforts. To start with, can firms identify customers with potential for high CIV during the acquisition stage? Are customers with high degrees of influence (e.g., individuals with large social networks) in social contexts likely to have influence when it comes to someone's product purchase decisions? Further, once these customers are identified, what are the best methods for acquiring these potential customers (discounts, samples, etc.)?

Similar questions are likely to arise regarding acquisition efforts using CKV. Can firms predict the customers who are likely to provide high levels of knowledge value to other customers? Some literature related to the value of social influence (i.e., CIV) is available but the literature related to customer knowledge (i.e., $\mathrm{CKV}$ ) is sparse.

\section{Growth}

Relatively little research has been conducted on the customer experiences that are effective for cross-selling. In other words, how could customer interactions during the shopping experience help firms identify opportunities for cross- or up-selling 
Table 1 Shopper marketing, customer relationship management, and customer engagement value

\begin{tabular}{lllll}
\hline & Acquisition & Growth & Retention & Win-back \\
\hline Pre-Purchase & CLV, CIV, CKV & CLV, CKV, CRV, CIV & & SCLV, SCRV \\
Purchase & & CLV, CKV, CIV & CLV & \\
Post-Purchase & & CRV, CKV & CRV & \\
\hline
\end{tabular}

All the CEV metrics in the table are meant to represent the net present value (NPV) of the potential value generated by a given customer through transactions (CLV), influence (CIV), knowledge sharing (CKV), and word of mouth/referrals (CRV) products and services? A basic example of cross-selling would be the recommender systems in Netflix. Grocery stores also shelve items that are complementary, such as pizza and soda, next to each other. Advances in big data and analytics can allow researchers to better understand shopping patterns using carts with RFIDs, mobile phone apps, or video cameras. These new data sources can allow us to identify opportunities for cross- or up-selling products and services during the customer shopping experience. While some current research identifies the effects of shopper experiences on product purchase, the customer engagement perspective urges researchers to consider more dependent variables.

It is also important to consider the role customer experience plays in increasing CRV or CIV, i.e., how it motivates customers to influence prospects directly through referrals or indirectly through sharing recommendations. Red Bull is an example of a firm that has developed it entire marketing strategy based on influencers. The firm actively recruits students in college campuses that are potential influencers, provides them training, and recruits them for running events that gather thousands of potential customers. Earlier in its launch phase, Red Bull actively recruited radio DJs and provided them product samples in exclusive events that they would then talk about on their shows.

While CLV and CIV customers are likely to increase value when purchasing well-developed and tested products across categories, the CKV customers may be more valuable during product development particularly in sectors such as software design, video game production, experiential services (e.g., instore virtual reality), or design of new store formats. Further, it would be important to understand how to best gather information from high CKV customers; is it better to keep these customers in isolation or as groups?

Starbucks provides a good example of post-purchase experience strategies for improving CKV. The firm has an online forum where it allows customers to provide product and service ideas. These ideas are then voted on by other members of the forum. Starbucks picks the ideas that obtain the highest votes for review. The firm then announces in the forum if they are launching these product ideas sourced from the forums. The idea providers are also highlighted prominently in these forums. Several of Starbucks' innovate ideas such as the green lids for the coffee cups were sourced from these forums.

\section{Retention}

A customer engagement perspective highlights the need to understand the link among customer retention, word of mouth (CRV) and influence (CIV). Firms would need to know the best mechanisms that motivate customers to talk about their experiences. Could they invite customers to blog about their experiences? And what type of customers would be interested in different firm-initiated post-purchase activities, those with higher CRV or CIV?

Significant research has been conducted on customer motivations for writing product reviews and how the aggregate measures of product reviews shape purchases. However, we know less about characteristics of reviews that other customers may find more or less valuable. Further, we know that reviews are often more effective when there are several available, compared to only one. This implies synergies among the customers in their influence value to the firm.

In network economies, customers may be not as profitable, but they add to the same- and cross-side network effects. For example, Gmail is more valuable to customers if others also use it. So, even if a Gmail customer is not individually valuable to Google from a CLV perspective, he or she can create same-side (and maybe even cross-side) network effects. Thus, customers who make no direct transactions (CLV) with a firm can still be important.

The major open issue regarding customer retention is whether models predicting churn of high CLV customers are also valuable in predicting how firms can retain customers which are valuable for knowledge (CKV), influence (CIV), and word of mouth (CRV). Are the customer experience variables more important in predicting retention for $\mathrm{CKV}, \mathrm{CIV}$, and CRV customers?

\section{Win-back}

In a customer engagement strategy, firms need to better understand whether to consider CLV, CKV, CRV, or CIV or a combination of these metrics when targeting customers for win-back. One assumption to test, for example, is if customers with high CIV would continue to influence others even if they are no longer a customer. Would the influence still have the same impact on potential customers even after the 
customer leaves the firm, and what strategies can firms use to win back customers who have a high influence or referral value? How do the CEV metrics vary between the first and second lifetimes?

In order to help summarize the research opportunities, I provide a summary table of questions which need to be addressed during each of the parts of the customer relationship life-cycle (see Table 2).

\section{Triggering conversations}

Success of an engagement strategy is dependent on customers developing an emotional attachment with the firm (Pansari and Kumar 2017). This requires an understanding of customers' motivations to engage with firms and maybe more importantly with other customers. But customers in general do not prioritize engaging directly with firms (Holt 2004).

Brands such as Dove, Red Bull, Patagonia, Chick-fil-A, and Whole Foods recognize this and have achieved a deeper level of engagement with their customers not by promoting the functional benefits of their products but by triggering conversations about social topics and issues that are important to consumers. This calls for brands to be part of the cultural landscape and play the role of promoter or enabler of (sometimes controversial) conversations (Holt 2004). Research on consumer identities and brand relationships would be very important to inform customer engagement researchers. Firms would need to recognize that brands can represent a broader set of identities including nationality (Pandya and Venkatesan 2016).

Being embedded in the broader cultural context also implies that brands and firms are exposed to exogenous shocks in the environment that may not be favorable. For example, consumers boycotted French sounding brands when when the French government did not support the U.S. invasion of Iraq.
Chick-fil-A experienced both boycotts and anti-boycott calls in reaction to its founder's statements on same-sex marriage. Research on the relationship of firms and brands to the broader social, cultural landscape is hence important for understanding the process for developing a robust customer engagement strategy.

\section{Organizing for an engagement orientation}

As firms begin to measure and manage customers across the different metrics of CEV, they face several implementation challenges related to managing customers from a multidimensional perspective. In the traditional customer-centric structure, key accounts represent highly profitable customers who justify a dedicated team. In an engagement-oriented firm, separate key accounts teams need to formed for high CLV, CRV, $\mathrm{CIV}$, or CKV customers. The structure, function, and communication among these account teams needs to be researched. The same customer can be part of multiple key account teams, and the experience of this customer needs to be consistent across them. This requires firms to systematically gather and share information about customers during pre-purchase, purchase, and post-purchase.

Success of an engagement-oriented approach lies in identifying synergies among the customer types to improve the firm's activities. For example, high CKV customers are important assets for developing new products, and also designing effective customer experiences for high CLV, CRV, and CIV customers. Leveraging such synergies would require coordination and communication across silos. Firms that can design and deliver personalized experiences for multiple customer preference and engagement segments will be most successful in implementing a customer engagement strategy. Big data, machine learning, internet of things, and artificial
Table 2 Summary of some off the key research questions to address by relationship stage

\section{Acquisition}

- Can firms identify identify potential customers who will have high influence (CIV) or knowledge $(\mathrm{CKV})$ ?

- What types of acquisition strategies will be more effective in acquiring customers who will have high CIV or CKV?

Retention

- How do experiences during purchases drive different aspects of CEV?

- How do actions by customers after purchases (e.g., writing a review or interacting with customers in a social network) influence other customers to make purchases?
Growth

- Are the cross-selling and up-selling strategies firms use to enhance CLV the same as those that will lead to increases in CIV, CKV, and CRV?

- Are certain CEV metrics more likely to create value earlier (e.g., CKV) vs. later (e.g., CIV) in the customer relationship?

Win-back

- How should firms use metrics such as CRV, CKV, and CIV in making decisions about which customers to win back?

- Are the strategies to win back customers different based on the value that the customer provides to the firm? 
intelligence technologies are enabling companies such as Disney, Amazon, Netflix, and Google deliver such personalized experiences even in physical environments.

An engagement orientation urges firms to co-create a wider range of activities with their customers (Harmeling et al. 2017) and requires every employee to be engaged with the firm and understand the value of customer engagement (Kumar and Pansari 2016; Menguc et al. 2017). It also requires alliances between organizations that go deeper through their respective supply chains. The structure of organizations and their internal and external eco-systems in such an environment is still an open question.

\section{Conclusion}

Customer engagement represents a new and exciting research agenda. My interactions with senior executives informs my belief that this is a priority for firms. But managers also recognize the challenges presented in developing and executing a customer engagement. This presents a great opportunity for academics to develop frameworks and insights that can guide effective customer management strategies. Combining insights from several research streams including customer relationship management, customer experience, social media, and customer-centric organizations would be key to developing actionable frameworks.

\section{References}

Harmeling, C., Moffett, J. W., Arnold, M. J., \& Carlson, B. D. (2017). Toward a theory of customer engagement marketing. Journal of Academy of Marketing Science, 45(3). doi:10.1007/s11747-0160509-2.

Holt, D. B. (2004). How brands become icons: the principles of cultural branding. Boston: Harvard Business Press.

Hollebeek, L. D., Shrivastava, R. K., \& Chen, T. (2017). S-D logic-informed customer engagement: integrative framework, revised fundamental proposition, and application to CRM. Journal of Academy of Marketing Science, 45(3). doi:10.1007/s11747-016-0494-5.

Homburg, C., Jozié D., \& Kuehnl, C. (2017). Customer experience management: toward implementing na evolving marketing concept. Journal of Academy of Marketing Science, 45(3). doi:10.1007 /s11747-015-0460-7.

Kumar, V., Aksoy, L., Donkers, B., Venkatesan, R., Wiesel, T., \& Tillmanns, S. (2010). Undervalued or overvalued customers: capturing total customer engagement value. Journal of Service Research, 13(3), 297-310.

Kumar, V., \& Pansari, A. (2016). Competitive advantage through engagement. Journal of Marketing Research, 15, 497-514.

Lemon, K. N., \& Verhoef, P. C. (2016). Understanding customer experience throughout the customer journey. Journal of Marketing, forthcoming.

Menguc, B., Auh, S., Yeniaras, V., \& Katsikeas, C. S. (2017). The role of supportive and hindering service climate: implications for service employee engagement. Journal of Academy of Marketing Science, 45(3).

Pandya, S. S., \& Venkatesan, R. (2016). French roast: consumer response to international conflict - evidence from supermarket scanner data. Review of Economics and Statistics, 98(1), 42-56.

Pansari, A., \& Kumar, V. (2017). Customer engagement: the construct, antecedents, and consequences. Journal of Academy of Marketing Science, 45(3). doi:10.1007/s11747-016-0485-6.

Venkatesan, R., Petersen, A., \& Guissoni, L. (2016). Could shopper marketing improve customer engagement. Working Paper. 